\title{
Participation rates and gender differences in enrolling patients for a randomized clinical trial evaluating the effect of audiovisual aids on perioperative stress response, pain and overall experience.
}

\section{Eva E. Mörwald MD*†, Crispiana Cozowicz MD*†, Katherine L. Lee BA*, Stavros G. Memtsoudis} MD PhD FCCP*

* Department of Anesthesiology, Hospital for Special Surgery, Weill Cornell Medical College New York, NY, USA † Perioperative Medicine and Intensive Care Medicine, Paracelsus Medical University, Salzburg, Austria

\section{Background:}

Enrolling patients in clinical trials can be challenging and reasons for non-recruitment are poorly understood. In compliance with the CONSORT statement1, data about patient recruitment is tracked as per routine for each randomized controlled trial at the Hospital for Special Surgery (HSS). Information on eligibility, attempted approach for consent, consent to participate and declination to participate for each patient screened is entered to a datasheet. We analyzed this data for a clinical trial about the effects of audiovisual aids (AVA) on perioperative stress response, pain and overall experience For the AVA trial patients undergoing arthroscopic meniscectomy under spinal anesthesia were enrolled. They were randomly assigned to either watch a movie using AVA or undergo surgery without distraction.

We hypothesized that a high percentage of patients would decline to participate and that there would be gender differences in the decision to do so.

\section{Materials and Methods:}

The AVA-Pilot Study was approved by the Institutional Review Board of HSS. Patient-enrollment for this trial started November 2015 and is still ongoing. We extracted data for patients who were approached for consent to participate in the AVA Pilot trial. This data was analyzed for rates of declination while taking gender into account. Data is presented as absolute numbers and percentages.

\section{Results:}

At the present date, $\mathrm{N}=63$ patients were approached to participate in this study. Of all patients approached $n=47(74.6$ $\%)$ were male. Of all patients approached $n=47(74.6 \%)$ declined to participate. Of the male patients $n=33(70.2 \%)$ declined and $n=14(29.8 \%)$ agreed while of the $n=16$ female patients $n=14(87.5 \%)$ declined and $n=2(12.5 \%)$ agreed to participate.

\begin{tabular}{l||c|c|c}
\multirow{2}{*}{} & \multicolumn{2}{c|}{ Declined } & Total \\
\hline \multirow{2}{*}{ Male } & 33 & 14 & 47 \\
\cline { 2 - 4 } Female & 14 & 2 & 16 \\
\hline \multirow{2}{*}{ Total } & 47 & 16 & 63
\end{tabular}

Table 1. Contingency table of the patients approached for the AVA Pilot trial. Patients are subdivided by gender and decision on participation.

Data is presented as $\mathrm{N}$

\section{Conclusions:}

Similar to findings in other clinical trials2,3 the percentage of approached patients that agreed to participate was low, especially among female patients. With the data currently available we cannot deduce if females declined because they did not want to be in a clinical trial, they disliked not knowing which treatment arm they would be in or due to the prospect of undergoing surgery without sedation in this specific trial. Collecting data about individual reasons to decline participation might help to develop methods to increase patient participation in general and female patients in particular.

\section{References:}

1. Moher D, Schulz KF, Altman DG, Group C. The CONSORT statement: revised recommendations for improving the quality of reports of parallel-group randomised trials. The Lancet 2001;357:1191-4.

2. Murthy VH, Krumholz HM, Gross CP. Participation in cancer clinical trials: race-, sex-, and age-based disparities. Jama 2004;291:2720-6.

3. Lee PY, Alexander KP, Hammill BG, Pasquali SK, Peterson ED. Representation of elderly persons and women in published randomized trials of acute coronary syndromes. Jama 2001;286:708-13. 